\title{
Effect of Different Defuzzification methods in a Fuzzy Based Liquid Flow control in Semiconductor Based Anemometer
}

\author{
Pijush Dutta ${ }^{1}$, Dr.(Prof) Asok Kumar ${ }^{2}$ \\ Department of Electronics \& Communication Engg., Global Institute of Management \& \\ Technology, India \\ Department of Electronics \&Communication Engg., MCKV Institute of Engg.,India
}

\begin{abstract}
Most of the process control technique is suffered by the complex dynamic systems with nonlinear or timevariable thats why it is very difficult to describe the behaviour of the system. One way to deal with the uncertainty of the behaviour of the system is to use fuzzy logic.If Fuzzy logic was modelled on spontaneous human reasoning then it captures the impreciseness the most input data which are inherent. In a fuzzy logic controller the focus is the human operator's behaviour, whereas in conventional PID controller what is modeled is the system or process being controlled.FLC regulator has a very good result from complex nonlinear dynamic processes, uses the reasoning of the human mind which is not always in the form of a yes or no. In this work, it shows overall effective control and operation of the mechanical equipments applied for control of liquid flow, implemented the fuzzy liquid flow algorithm and compared the effect of using different defuzzification methods. Flow control system takes information about sensor output voltage, control valve opening \& flows rate as parameters and controls in case of overflowing \& wastage.In this design two input parameters: sensor output voltage and rate of change voltage and one output parameters: opening of the control valve.
\end{abstract}

\section{KEYWORDS}

Liquid flow Process, Fuzzy logic, Defuzzificaton

\section{INTRODUCTION}

In most industrial application the liquid flow control is a preeminent importance, especially in food processing, petrochemicals and pharmaceutical industries In industries it is difficult to control the large dead time in a flow control system [1], that's why the controller is designed is such a way to maintain the set point and able to adopt a new set point value automatically. Control of the fluid flow between the tanks is a fundamental requirement in most of the process industries. Stabilizing the liquid flow of a plant around a predetermined level is an important problem of dynamics of those systems has nonlinear characteristics[5].In our study, a water flows control process, is used to observe trajectories tracking performance.

The conventional PID controller cannot give the effective action before the error is developed, it can only initiate the control action after the error has developed. To achieved the better corrective action in advance and better performance in this paper i use fuzzy logic controller instead of the conventional PID controller [2]. fuzzy control technique receives many attentions due to its resemblance to human-like characteristics. In this paper the reservoir operation is modelled by the fuzzy logic based intelligent control approach, which operates by 'if-then' knowledge base logic, where the flow rate \& change in flow-rate are the 'if' fuzzy explanatory variables while opening the control valve is a 'then' is a fuzzy consequence [11].Here in this 
paper various defuzzification methods are implemented in a tank water flow control system [4] $\&$ results are compared and optimization is achieved.

\section{Basic Structure of The Proposed System}

The main purpose of the water flow control process is to keep the water flow in the tube at desired rate and track the reference point .Here water is considered as the liquid to check the non linearity of the cylindrical tank. Reservoir tank collects the water which is pumped to the cylindrical tank. Flow is calculated by using anemometer type flow sensor. The output of the anemometer is converted into analogous current which controlled by the controller action is taken by the controller action .last sections of the controller converted the analog signal from I/V converter are converted into Digital Form by using ADC. The signal from ADC is acquired by using PC output signals from $\mathrm{PC}$ is given as the input to the DAC which convert the digital to analog form which is further converted to current signals from V/I converter. Control valve gets pressure signal from $\mathrm{I} / \mathrm{p}$ converter Which controls the input flow to the cylindrical tank Depending on the control signal(voltage), pneumatic control valve allows the water flow into tubes from the tank and causes flows rate change in the tube. The operation is repeated throughout the control process till the water flow rate of the tube is same to the reference. Here sensor o/p voltage $\&$ change in sensor voltage (obtain from the sensor which produce the linear decrease voltage with increasing the flow rate) is the input of the fuzzy logic controller of the paper while the (\% of the openness)positioning of the pneumatic control valve is output .

The controller action is taken by the controller action .last sections of the controller converts the analog signal from I/V converter are converted into Digital Form by using ADC. The signal from $\mathrm{ADC}$ is acquired by using $\mathrm{PC}$ output signal from $\mathrm{PC}$ is given as the input to the DAC which convert the digital to analog form which is further converted to current signals from V/I converter Control valve gets pressure signal from $\mathrm{I} / \mathrm{p}$ converter Which controls the input flow to the cylindrical tank .Depending on the control signal(voltage),pneumatic control valve allows the water flow into tubes from the tank and causes flows rate change in the tube. The operation is repeated throughout the control process till the water flow rate of the tube is same to the reference. Here sensor $\mathrm{o} / \mathrm{p}$ voltage \& change in sensor voltage (obtain from the sensor which produce the linear decrease voltage with increasing the flow rate)of the input of the fuzzy logic controller of the paper while the ( $\%$ of the openness)positioning of the pneumatic control valve is output .

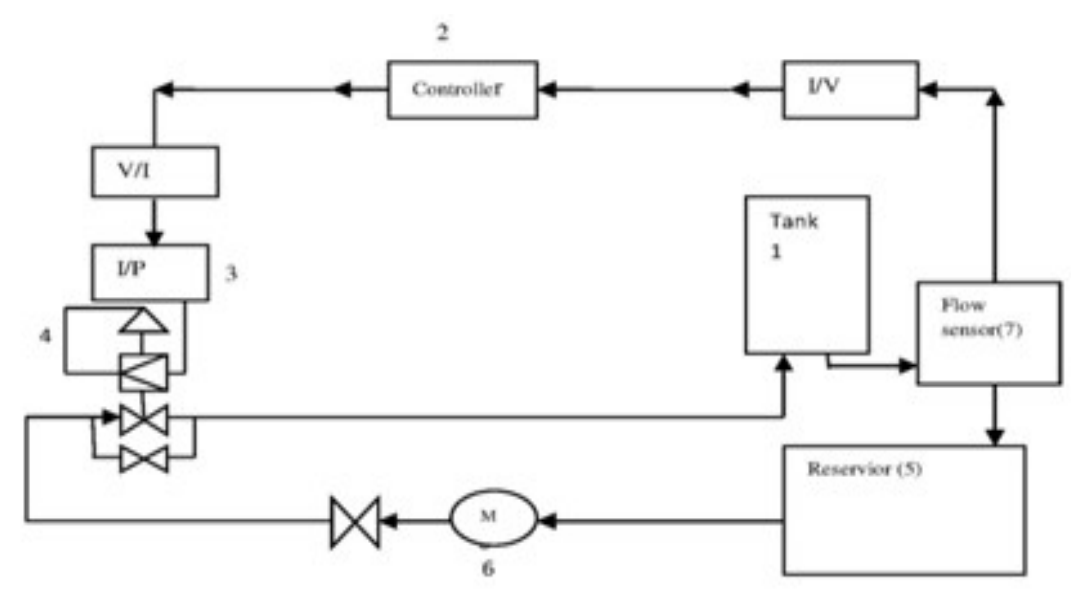

Fig.1. closed loop process control diagram 


\section{Fuzzy Logic Controller}

Fuzzy logic controllers is a non mathematical decision algorithm[10]that is based on the operators experience that's why this logic controller is suited for the non linear system such as liquid flow control which exhibits non linear relations between the sensor output (flow rate ) \& percentage of opening of pneumatic control valve of the system. The first input of the Fuzzy logic controller is immediate sensor output voltage when compared to the reference voltage to tell the controller that if the sensor voltage needs to be increased or lowered (flow rate decreased or increased).The second input to the controller is the rate of change of voltage. This input describes how fast the ouput voltage is changing. This is an important factor of a real time control system .for example if the rate of change voltage is lower than its rated voltage then the closeness of the pneumatic control valve is closed slowly to bring the rate of change voltage at rated value. In another case if the rate of change is greater than the rated voltage of the sensor output then the closeness of the pneumatic control valve closed very fast to bring the value of rated .The output of the fuzzy logic control is a positioning of the pneumatic control valve .

By changing the position of the control valve the flow rate as well as the output voltage of the anemometer sensor is controlled. This can be seen in figure no.1.Figure no. 2 shows the variables of the fuzzy logic controller.

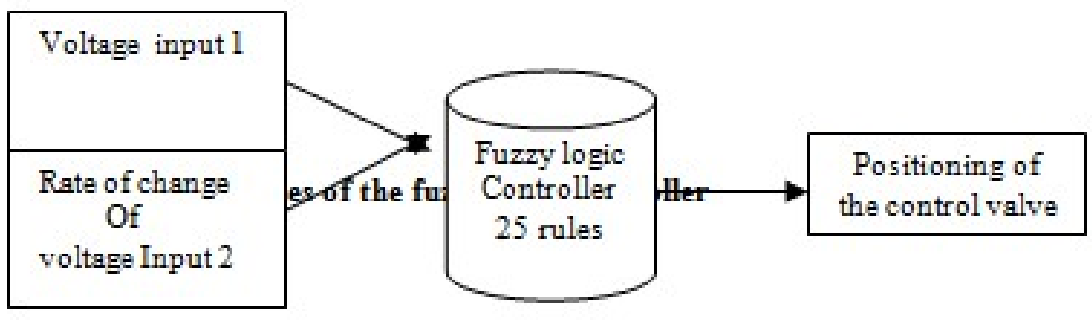

Fig 2. Variables of the fuzzy logic controller

\section{FUZZIFIER}

Fuzzy logic is represented by the linguistic variables instead of numerical variables. In a closed loop control system, error (e) can be labelled as Very low, low, Nomal, Large \& Very Large, while rate of change of error labelled as Negative Large, Negative Small, Normal, positive Small \&Positive Large. In the real world, measured quantities are real numbers or crisp variables.Fuzzification is the the process for converting a numerical variable (real number) into a linguistic label (fuzzy number).Figure3. Shows the membership functions that are used as input \& output for fuzzify.

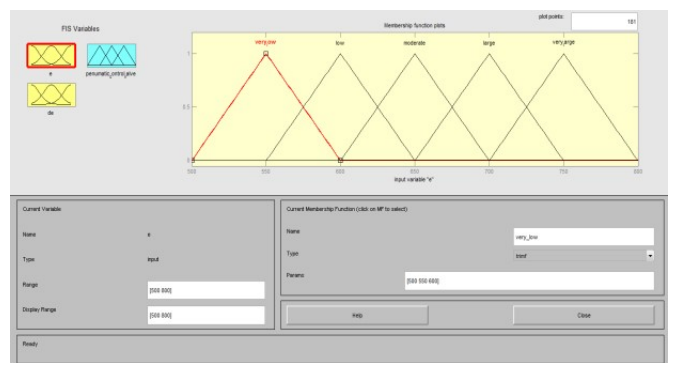

Input \#1: voltage (volts)

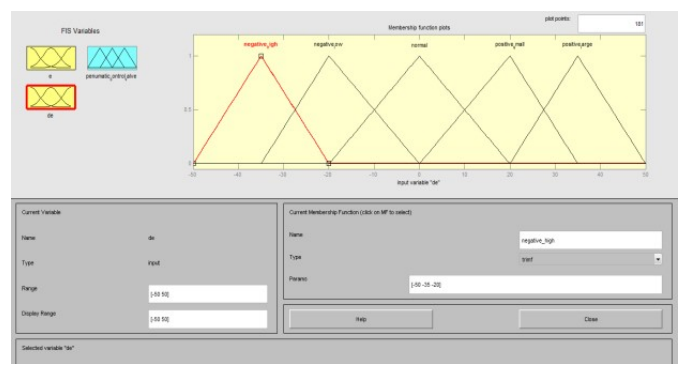

Input \#2 : delta voltage (volt/sec) 


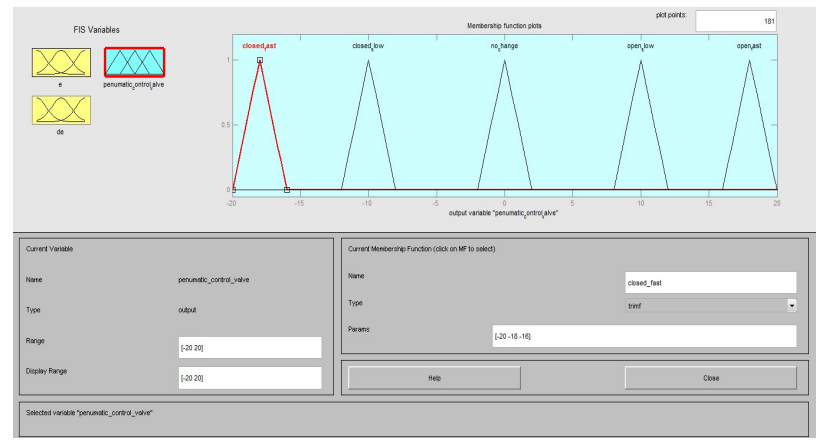

Output \#1: positioning of the control valve

Figure 3: Membership function of the Fuzzy logic controller

\subsection{INFERENCE}

In conventional controllers, the reaction to the controller can be governed by generating the control laws with the help of combinations of numerical values. In fuzzy logic control, above concepts is equivalent to the term is rules. Fuzzy Logic Rules are linguistic in nature and precise the operator to develop a control decision in a familiar human environment [4]. A typical rule can be written as follows:

If the "voltage" is very Low AND the "rate of change of voltage error" is negative large, then the "the positioning of the control valve" is closed slowly So on

In this system a minimum correlation inference technique is used that means the logic operation of AND will consider the minimum of the two input .For the fuzzy linguistic variable the output variable positioning of the control valve would receive the membership function which was equal to the minimum of the two input. The rules of the fuzzy controller give the intelligence by applying the rules by a person that has an experience with the system to be controlled. In the case of fuzzy logic liquid flow rate controllers, the main aim are to keep the output voltage of the sensor at its rated value. To obtained the desired goal the rules are made for every combination of voltage \& rate of change error voltage on which the positioning of the control valve is stabilizing. It is convenient to put the rules of the form of rule table for dealing with the large no. Of input membership functions.

Table 1.Fuzzy logic rule table

\begin{tabular}{|l|l|l|l|l|l|}
\hline $\begin{array}{l}\text { Voltage } \\
\text { Delta voltage }\end{array}$ & Very low & low & Normal & Large & Very large \\
\hline Negative Large & $\begin{array}{l}\text { Closed } \\
\text { slow }\end{array}$ & Closed slow & Open slow & Open fast & Open Fast \\
\hline Nagative Small & $\begin{array}{l}\text { Closed } \\
\text { slow }\end{array}$ & Closed slow & Open Slow & Open Fast & Open Fast \\
\hline Normal & Closed fast & Closed slow & No change & Open slow & Open Fast \\
\hline Positive Small & Closed fast & Closed fast & Closed slow & Open slow & Open slow \\
\hline Positive Large & Closed fast & Closed fast & Closed fast & No change & Open slow \\
\hline
\end{tabular}

In Defuzzification each membership function of the output variables will contain a correepondng membership function and produced crisp values. 


\subsection{DEFUZZIFICATION}

Defuzzification plays a great role in an intelligent based control system It is the process in which the fuzzy quantities defined over the output membership function is mapped into a non-fuzzy number or a crisp variable. It is impossible to convert a fuzzy set into a numeric value of loosing some information. Many different methods exist to accomplish defuzzification. Naturally there are trade-offs to each method. In this paper the following five defuzzification methods are performed.
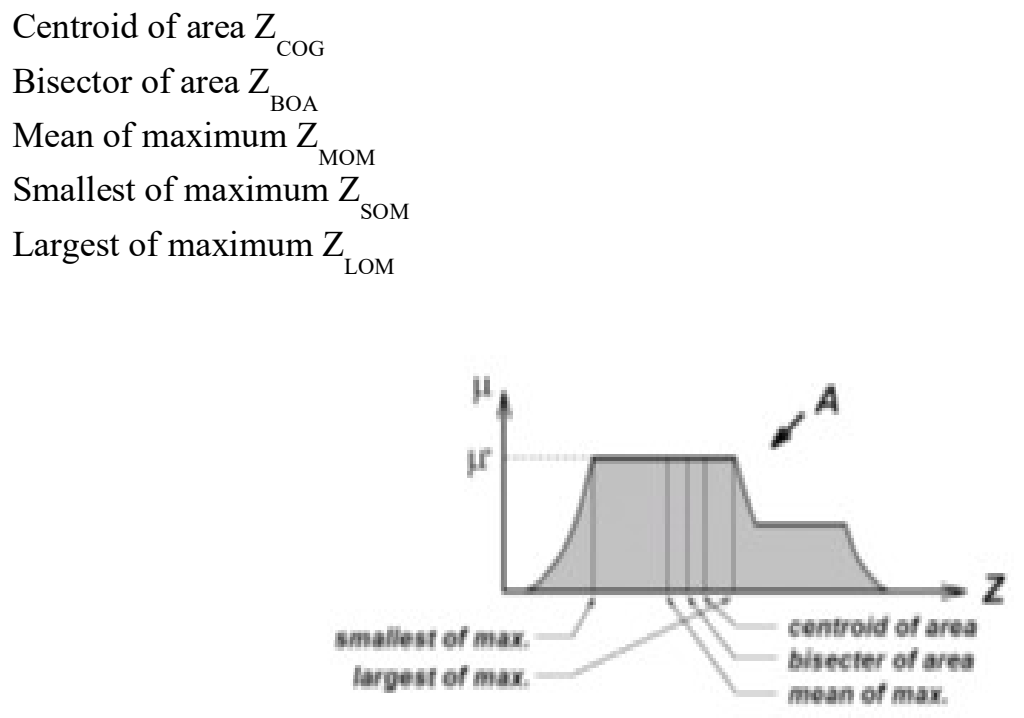

Figure 4: Results using different defuzzification methods for a particular function

\subsubsection{Centroid Principle Or Center Of Gravity (COG)}

This method is also known as center of gravity or centre of area defuzzification method, the fuzzy logic controller first calculates the area under the scaled membership functions and within the range of the output variable. The only limitation is that it is unable to compute the complex membership functions.

\subsubsection{BISECTOR METHOD}

The bisector defuzzification method the vertical line divides the whole region into two subregions of equal area. Most of the cases its coincident with the centroid line.

\subsubsection{LARGEST OF MAXIMUM (LOM)}

In Largest of Maximum defuzzification method it chooses the largest crisp value $\mathrm{Z}_{\text {LOM. }}{ }^{\text {amongst }}$ all $\mathrm{z}$ that belong to $[\mathrm{z} 1, \mathrm{z} 2]$.

\subsubsection{SMallest OF MAXIMUM (SOM)}

In Smallest of Maximum defuzzification it selects the smallest crisp value $Z_{\text {som }}$ amongst all $\mathrm{z}$ that $\mathrm{z}$ that belong to [z1, z2]. 


\subsubsection{MEAN OF MAXIMUM (MOM)}

This type of defuzzification with the highest degree of fulfillment are taken into account that is it selects the highest degree of membership function as crisp value.

\section{INTERPRETATION OF RESULTS}

The interpretation result is obtained on a Matlab scheduler by taking two input parameters voltage \& rates of error voltage and one output parameter. We measure the input parameters voltage \& rate of error voltage on a scale 500-800 \& $-50-50$ respectively and the output parameter positioning of the control valve on a scale of $-20-20$. Based upon the crisps value that are obtained the positioning of the control valve are categorized . in this system this crisps value is calculated using the five defuzzification methods described above. The surface plots which are obtained from the different defuzzification are shown in Figures 5 to 9 and the input and output values are obtained for 21 sets of data is shown in Table 2 .

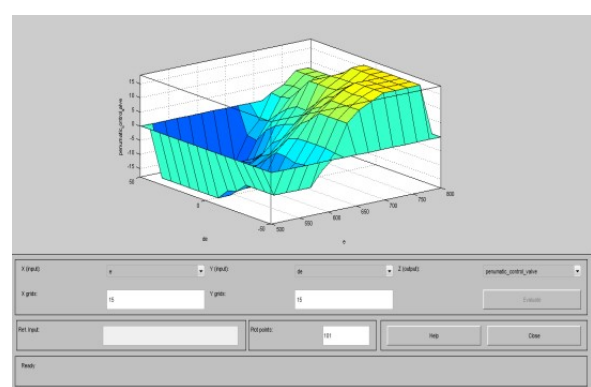

Fig.5 Centriod method

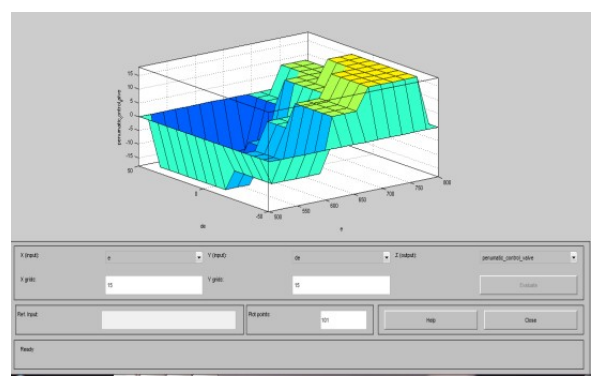

Fig .7.Mean of maximum method

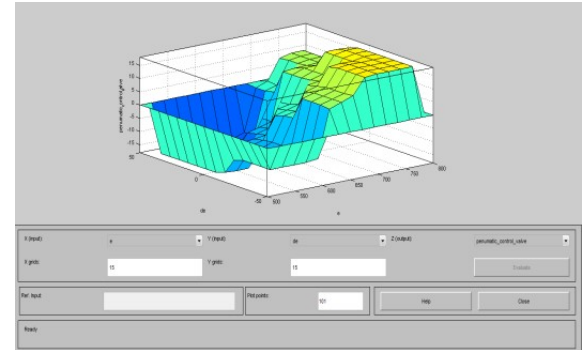

Fig.6.Bisector method

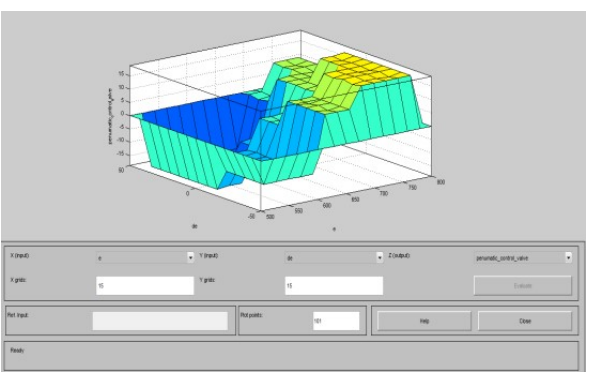

Fig.8.Largest of maximum method

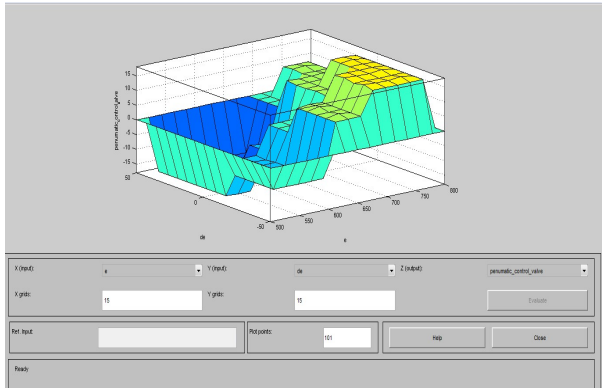

Fig.9 Smallest of maximum method 
Table 2: Output values btained for different defuzzification methods.

\begin{tabular}{|c|c|c|c|c|c|c|c|}
\hline \multirow{2}{*}{ SI No } & \multicolumn{2}{|c|}{ Input variables } & \multicolumn{5}{|c|}{ Output variables } \\
\cline { 2 - 8 } & $\mathrm{E}$ & $\mathrm{De}$ & Centriod & Bisection & MOM & LOM & SOM \\
\hline 1 & 500 & -50 & 0 & 0 & 0 & 0 & 0 \\
\hline 2 & 510 & -45 & -10 & -10 & -10.2 & -11.6 & -8.8 \\
\hline 3 & 520 & -40 & -10 & -10 & -10.2 & -11.2 & -9.2 \\
\hline 4 & 530 & -35 & -10 & -10.2 & -10.2 & -10.8 & -9.6 \\
\hline 5 & 540 & -30 & -10 & -10 & -10 & -10.4 & -9.6 \\
\hline 6 & 550 & -25 & -10 & -10 & -10 & -10.4 & -9.6 \\
\hline 7 & 560 & -20 & -10 & -10 & -10.2 & -10.4 & -10 \\
\hline 8 & 570 & -15 & -12.7 & -10.8 & -10.2 & -10.8 & -9.6 \\
\hline 9 & 580 & -10 & -13.7 & -11.2 & -10 & -10.8 & -9.2 \\
\hline 10 & 590 & -5 & -12.2 & -10.4 & -10 & -10.4 & -9.6 \\
\hline 11 & 600 & 0 & -10 & -10 & -10 & -10 & -10 \\
\hline 12 & 610 & -50 & 0 & 0 & 0 & 0 & 0 \\
\hline 13 & 620 & -45 & 1.71 & 8.4 & 0 & 11.2 & -8.8 \\
\hline 14 & 630 & -40 & 1.35 & 8.8 & 9.8 & 10.4 & 9.2 \\
\hline 15 & 640 & -35 & 4.55 & 9.6 & 9.8 & 10 & 9.6 \\
\hline 16 & 650 & -30 & 10 & 10 & 10 & 10.4 & 9.6 \\
\hline 17 & 660 & -25 & 12.3 & 10.4 & 10 & 10.4 & 9.6 \\
\hline 18 & 670 & -20 & 13.5 & 11.2 & 9.8 & 10.4 & 9.2 \\
\hline 19 & 680 & -15 & 11.3 & 11.2 & 17.8 & 18.4 & 17.2 \\
\hline 20 & 690 & -10 & 11.3 & 10.8 & 14 & 18.8 & 9.2 \\
\hline 21 & 700 & -5 & 12.5 & 10.4 & 10 & 10.4 & 9.6 \\
\hline & & & & & & & \\
\hline
\end{tabular}

\section{CONCLUSION \& Future WORK}

The comparative result is obtained using the five defuzzification methods have been shown in table2\& waveform 5to9.From this table it is seen that centroid and bisector method are giving the approximately same results from liquid flow control process application that we have taken. Where as for mean of maximum method gives moderate result but the smallest of maximum and largest of maximum approaches wide variations in the results due to the smallest or largest values for calculation of the crisp value. The results obtained in the tables above are graphically shown in figures 5 to 9 for the same input variables. In this work due to the more consistency in the results centroid, bisector and MOM methods are better compared to the LOM, SOM. By using these defuzzification methods this work can be further extended to find out how process effect on response time.

\section{REFERENCES}

[1] Niimura, T. and Yokoyama, R., "Water level control of small-scale hydro-generating units by fuzzy logic" Proceedings of IEEE International Conference on Systems, Man and Cybernetics, pp. 483,1995 .

[2] Roubos,J.A., Babuska,R., Bruijn,R.M. and Verbruggen,H.B., "Predictive Control by Local Linearizatin of a Takagi-Sugeno Fuzzy Model”, IEEE Transactions, 1998. 
[3] Ghwanmeh,S.H., Jones,K.O. and Williams,D., "On-line Performance Evaluation of a SelfLearning Fuzzy-Logic Controller Applied to Non-Linear Processes”, IEEE Transactions, 1996.

[4] Riyaz Shariff, Audrey Cudrak and Qing Zhang "Advanced process control techniques for water treatment using artificial neural networks".

[5] J. Environ. Eng. Sci. 3(S1): S61-S67 (2004).[6] Xiao,Y., Hu,H., Jiang,H., Zhou,J.and Yang,Q., "A Adapti- tive Control Based Neural Network for Liquid Level of Molten Steel Smelting Noncrystlloid Flimsy Alloy-Line", Proc. of 4th World Congress on Intelligent Control and Automation, China, 2002.

[6] Takagi,T. and Sugeno,M., "Fuzzy Identification of System and its Applicaiton to Modeling and Control", IEEE Transactions on Systems, Man and Cybernetics, Vol.15, No.1, 1985.

[7] Tan, K.K., Lee, T.H., Hunag, S.N. \& Leu, F.M., "PID control design based on a gpc approach," Industrial \& Engineering Chemistry Research 41(8), 2002.

[8] C. Cutler and B. Ramaker, "Dynamic Matrix Control: A Computer Control Algorithm," Pror. 1980 Joint utoniatic Coritrol Conference.

[9] Katsuhiko Ogata, "Modern Control System", 3rd edition, Prentice Hall, Upper Saddle River, New Jersy -7458 .

[10] M. Jamshidi, "Fuzzy Logic and Control, Software and Hardware Applications", University of New Mexico PTR Prentice-Hall, Inc. Ch 1-4, 1993.

[11] Elangeshwaran Pathmanathan, Rosdiazli Ibrahim, "Development and Implementation of Fuzzy Logic controller for Flow Control Application,” Intelligent and Advanced Systems (ICIAS), International conference on Digital Object Identifier, pp.1-6, 2010.

[12] Heon Young Yang, Sung Han Lee, Man Gyun Na, "Monitoring and Uncertainty Analysis of Feedwater flow Rate Using Data-Based Modeling Methods", IEEE transactions on Nuclear Science, vol. 56, No 4, pp2426 - 2433, August 2009.

\section{Authors}

Pijush Dutta : He received the Bachelor's Degree in the Department of Electronics \& communication Engineering Dept.\& Masters Degree in the Department of Mechatronics from West Bengal University of Technology, India, in 2007 and 2012 respectively. He is currently assistant professor in the department of ECE Department, in Global Institute of Management Technology, Krishnagar, India.His research are is intelligence system \& sensor \& transducer .

Dr(Prof). Asok Kumar : He received the Bachelor \& Masters in the Department of Radio Physics \& Electronics from Calcutta University, India in 1997 \& 1999repectively.He received His Phd Degree from Jadavpur university from 2007.He has more than 50 international \& national journal. His research fields are coding, communication sensor \& Transducer \& intelligence system.
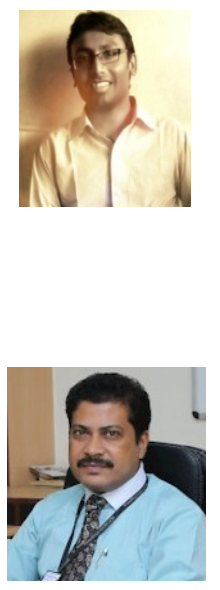